\title{
COLLECTION OF URINE AND FAECES IN CHILDREN, WITH A NOTE ON FAT BALANCES
}

\author{
BY \\ EUNICE M. BALDWIN, BARBARA E. CLAYTON, P. JENKINS, J. MITCHELL \\ and A. G. C. RENWICK \\ From The Hospital for Sick Children, Great Ormond Street, London
}

(RECEIVED FOR PUBLICATION APRIL 12, 1962)

With care and patience, complete collections of urine and faeces can be obtained from infants and incontinent children, and metabolic studies to the standards acceptable in adults are practicable.

\section{Collection of Urine}

In 1959, Wilkinson and Baldwin described a disposable plastic urine collector for use in boys and girls. In the light of further experience this has been modified and the new bag is illustrated in Fig. 1. Two sizes of bag are available as before: bags of 8 in. $\times 3$ in., and 12 in. $\times 4$ in., for babies up to 3 months and over 3 months respectively. The new bag differs from the older pattern, first in having no hole for the anus, the plaster being of such a size that it terminates just before the perineum reaches the anus, and secondly in having a pattern for three sizes of genitalia stencilled on both sizes of plaster, thus making it easier to fit the plaster.

Instructions for Fitting Urine Collector. Correctly fitted bags on a boy ard girl are shown in Figs. 2 and 3.

Make quite sure that the skin is free from spots, cracks and abrasions. Wash the area with soap and water, and dry carefully in the normal way. Do not, however, apply creams, lotions or talcum powder.

Using the stencilled guide lines, cut the hole in the plaster to the correct size for each child. The paper covering the adhesive surface of the collection bag should now be removed.

The patient should be placed flat on a cot or bed and not allowed to remain lying on his mother's or a nurse's knee while the bag is being applied.

Careful application is necessary if the best results are to be obtained. One nurse should fit the appliance while a second nurse holds the child firmly. Flex and separate the thighs; then gently stretch the skin laterally so that the groove down to the perineum is as shallow as possible.

The collection bag should be held with the end ' $X$ ' (Fig. 1) towards the patient's feet. The adhesive surface surrounding the opening in the plaster is then applied to the skin. First of all it must be stuck to the skin right across the perineum, particularly in the midline, and then, gradually working upwards, the adhesive plaster with the bag attached is stuck around the patient's genitalia so that they protrude into the bag.

Having attached the bag firmly to the skin, cut a minute hole in one proximal corner, just large enough to insert a very fine rubber catheter. This should be long enough to reach the end of the bag and enable urine to be withdrawn with a syringe. The catheter is then secured with a small piece of elastoplast. As the catheter may need to be adjusted from time to time, the use of zinc oxide strapping is not advised as it is too adhesive and may cause the bag to be dislodged if a nurse pulls too hard on the plaster.

A knot should be tied in the end of the catheter which protrudes from the bag. This may be readily untied and attached to a syringe when the bag requires emptying. The free end is then either tucked out of sight inside the child's pants or trousers, or inside a nappy. The use of a spigot is not advised as it may fall out or be removed by exploring fingers.

The success of this method of collection depends on regular observation every 15 minutes and prompt emptying of the bag. If the bag is allowed to remain full it will become very uncomfortable, the weight of urine will eventually dislodge it and there will be leakage. This method allows the child to remain ambulant. It is not necessary for him to remain in bed.

Should there be an apparent leak in the collection bag or fault in the plaster, always apply a new 


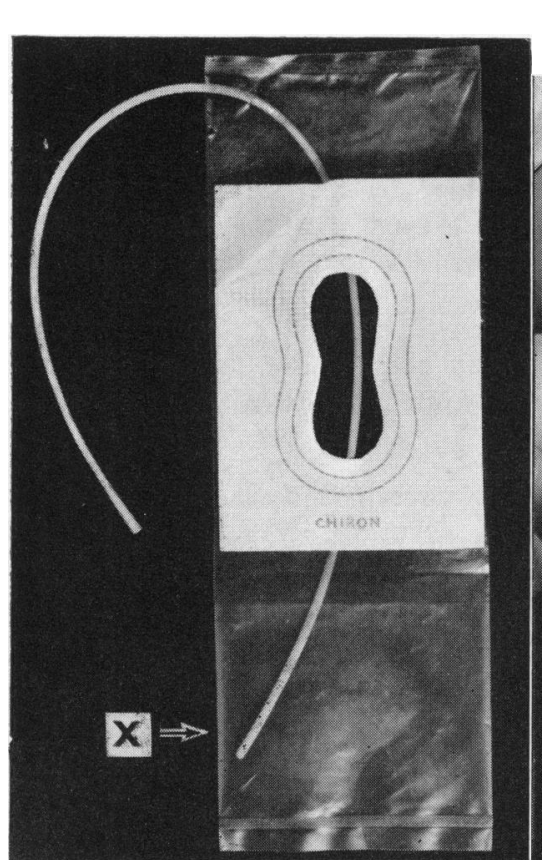

FIG. 1.-Urine collecting bag, 1962 pattern

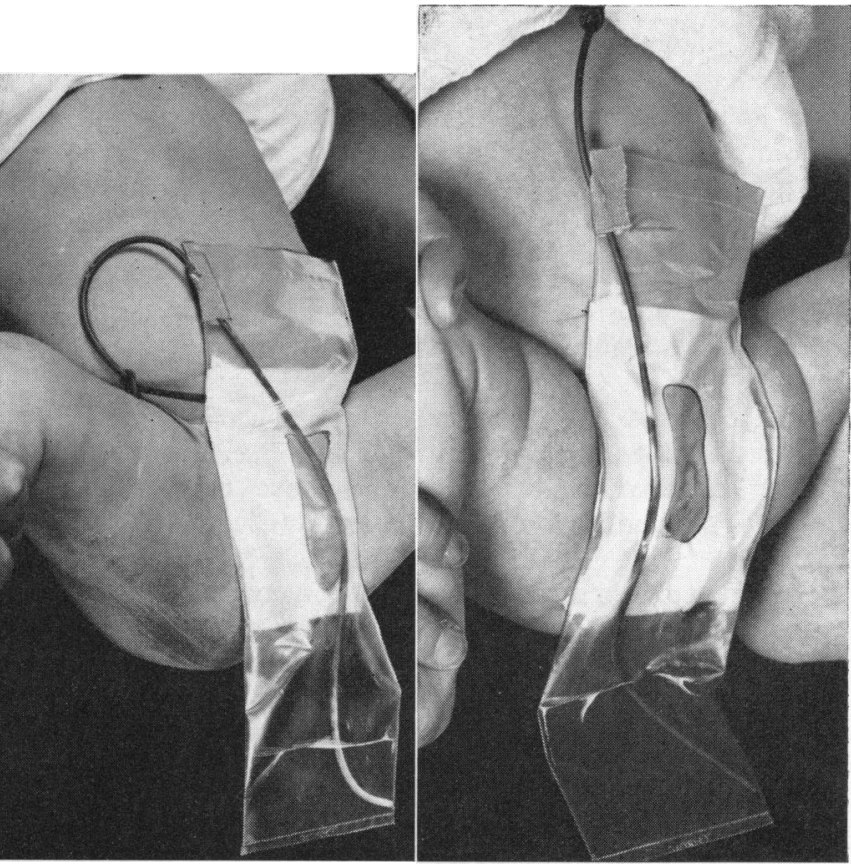

FIG. 2.-The urine collecting bag fitted on a boy.
FIG. 3.-The urine collecting bag fitted on a girl. collection bag. Never attempt to reinforce with pieces of adhesive strapping.

If after a few days the skin on the plaster area appears to be breaking down, stop the collection at a convenient time (e.g. at the end of a 24-hour collection) and recommence at a later date. The use of special creams or lotions is not usually necessary, and rest for one or two days is usually sufficient for complete recovery. A small square of vaseline gauze (tulle gras) is often helpful if applied over the sore area in small babies; this will protect the skin from faeces.

Important: Never attempt to remove the collection bag if it is full, but always empty it first with a syringe. If this is not done, the urine will escape via the hole cut for application.

As an added precaution to ensure completeness of collection in very small active babies, a square of polythene sheeting* can be placed inside the nappy. The urine will then remain free and not soak into the linen. Loops made from adhesive tape should be attached to the corners of the square of sheeting, and the loops pinned to the nappy with large safety pins.

\footnotetext{
* Warning: Polythene sheeting must be stored in a safe place away from children because of the dangers of suffocation. It must never be placed loose on a cot or bed, or used as a bib.
}

\section{Collection of Faeces}

The child's nappy is lined with fine polythene sheeting (75 gauge); a number of materials have been used, but this has been the most successful and is the least likely to cause soreness of the buttocks on repeated use. After the stool has been passed, the polythene sheeting is lifted carefully into a screw-topped wax container which is labelled on the container (not the lid) with the name, date and time. For older, col tinent children, the potty is lined with a large piece of the sheeting. After deep-freezing, the sheeting is easily pulled off the faeces. Scraping up faeces from nappies and containers by nursing and technical staff is thus eliminated.

For timed faecal collections it is necessary to give a marker. Charcoal is not satisfactory. It is helpful to use a red and a blue marker alternately:

1. Red marker: Carmine powder, grains 3 and 5 for under 1 year of age and over 1 year respectively.

2. Blue marker: Edicol Supra Blue E.G.* $1 \mathrm{mg}$. $\mathrm{kg}$. body weight.

The blue marker is unsatisfactory if the stools are very loose, and in this case it is necessary to use

\footnotetext{
* Imperial Chemical Industries Ltd.
} 
carmine markers only. The markers may be dissolved in a little water and given from a feeding bottle or cup. For timed collections of stools the interval between markers is usually five days, but for infants three days is frequently satisfactory and more convenient.

\section{Conduct of Fat Balances}

Accurate five-day fat balances of the type normally used in adult patients can be performed equally well in children.

With the introduction of the polythene sheeting and waxed cartons, expert nursing is not essential for older children, and fat balances have been performed satisfactorily on out-patients (Clayton and Cotton, 1961).

The child is placed on a diet containing a constant amount of fat, the quantity being similar to his normal intake. Any rejected food is collected and the fat in it is estimated chemically. Two different markers are given five days apart. The five-day collection of stools for estimation commences with the first appearance of the marker and ends with, and includes, the stool passed immediately before the second marker appears. Experience has shown that for successful balances the nurses or mother should send all the stools to the laboratory from the time when the first marker is given up to and including the unmarked stool following the stool(s) containing the second marker. The responsibility for selecting the correct stools then becomes that of the laboratory technician; there is then no reason for the nurse or mother to discard a stool or for her to have to decide whether a stool is marked or not. Occasionally a stool may be part coloured and it will have to be divided as necessary.

The stools which are easily removed from the polythene sheeting are placed in a calibrated jar, made up to a volume of $500 \mathrm{ml}$. with water and homogenized with a Silverson homogenizer. While the homogenizer is running, duplicate samples of homogenate are removed with a syringe having a wide piece of polythene tubing fitted to the nozzle. Fat is determined by the wet method of Kamer, Huinink and Weyers (1949). Apart from premature infants, in whom absorption is lower and more variable, $95 \%$ of the fat is usually absorbed. Values between 90 and $94 \%$ are not necessarily indicative of an abnormality, and clinical findings must be taken into account when interpreting the result.

It has been a pleasure to design the urine collecting bag with Mr. S. Gaillard of Down Bros. and Mayer and Phelps. Dr. W. H. W. Inman kindly suggested and supplied the blue marker. We thank the nursing staff for all their useful comments during the elaboration of the techniques described. We are grateful for the assistance of the Department of Medical Illustration.

\section{REFERENCES}

Clayton, B. E. and Cotton, D. A. (1961). A study of malabsorntion after resection of the entire jejunum and the proximal half of the ileum. Gut, 2, 18.

Kamer, J. H. van de, Huinink, H. ten Bokkel, and Weyers, H. A. (1949). Rapid method for the determination of fat in feces. J. biol. Chem., 177, 347 .

Wilkinson, R. H. and Baldwin, E. M. (1959). A simple urine collector for infants. Brit. med. J., 2, 428.

\section{Suppliers of Special Items}

1. Great Ormond Street pattern plastic bag urine collector, 1962 pattern. Down Bros. and Mayer and Phelps Ltd., 32-34 New Cavendish Street, London W.1.

2. Polythene sheeting 75 gauge. Transatlantic Plastics Ltd., 29 Victoria Road, Surbiton, Surrey.

3. Screw-capped waxed containers, sizes 100 and 120 . Monocontainers Ltd., Park Royal, London N.W.10.

4. Self-adhesive paper labels (super-tack quality) suitable for plastic and waxed containers stored in a deep-freeze. Multitapes Ltd., Park End, South Hill Park, London N.W.3.

5. Silverson homogenizer (Silverson Laboratory Mixer-Emulsifier). Silverson Machines (Sales) Ltd., 55-57 Tower Bridge Road, London S.E.1.

N.B. There is now a new model available with totally enclosed rotor arm, thereby minimizing aerosol formation. 